\title{
Chitosan based nano-membrane for Chromium(III) Determination in Pharmaceutical and Foodstuff Samples
}

\author{
S. Khalil ${ }^{1, *}$, A.E. El-Beltagy ${ }^{1}$, M.E.A. El-Sayed ${ }^{1}$, A.A. Abdel Fattah ${ }^{1}$, Y.F.M. Kishk ${ }^{1}$ and Salman S. \\ Alharthi $^{2}$ \\ 1 Department of Food Science and Nutrition, College of Science, Taif University, Taif 21944, P. O. \\ Box 11099, Saudi Arabia. \\ 2 Department of Chemistry, College of Science, Taif University, Taif 21944, P. O. Box 11099, Saudi \\ Arabia. \\ *E-mail: $\underline{\text { S_Khalil_99@Yahoo.co.uk \& Sabry@Tu.edu.sa }}$
}

Received: 8 July 2021 / Accepted: 12 August 2021 / Published: 10 October 2021

\begin{abstract}
A newly fabricated chromium selective liquid electrode sensor was successfully designed according to the reaction between nano-chitosan and chromium(III) ions. The characteristics specific slope ( 58.5 $\mathrm{mV} /$ decade $)$, linearity range of concentration from $1.0 \times 10^{-6}-1.0 \times 10^{-1} \mathrm{M}$, the limit of detection $\left(1.32 \times 10^{-}\right.$ $\left.{ }^{8}\right) \mathrm{M}$, selectivity behavior among some inorganic cations, the dynamic response time(10s), lifespan (four months),the potential dependence on $\mathrm{pH}$ and basic interesting validations and parameters were investigated. The nominated electrode was successfully utilized to detect chromium(III) ions in pharmaceutical and foodstuff samples. The data provided by the developed sensor were treated, statistically and compared with other electrodes listed in the literature.
\end{abstract}

Keywords: Membrane sensor,Nano-chitosan, Chromium ions, Pharmaceutical and Foodstuff samples

\section{FULL TEXT}

(C) 2021 The Authors. Published by ESG (www.electrochemsci.org). This article is an open access article distributed under the terms and conditions of the Creative Commons Attribution license (http://creativecommons.org/licenses/by/4.0/). 